\title{
Deflection Calculation for Beam-type Structures from Measured Strain Data
}

\author{
Željko FLAJS, Emil VEG, Nenad GUBELJAK, Goran ŠINIKOVIĆ
}

\begin{abstract}
Behavior of structures under various load types is determined by their deformation characteristics, global deformation characteristics - deflections and rotations, and local deformation characteristics - strains / stresses in structure base material. If we know global and local deformation characteristics of a structure, then it is possible to determine the structure behavior under acting loads, on the whole structure or at some part of that structure. The main objective of this research is to verify calculation algorithm for obtaining vertical displacements - the deflection of the structure, based on the known strain values in the structure base material, under acting load. The verification of the calculation algorithm is performed by comparing the numerical and experimental results.
\end{abstract}

Keywords: calculation algorithm; numerical and experimental results; structure; vertical deflections

\section{INTRODUCTION}

In order to monitor the condition of structures under active load, electronic systems are being installed on an increasing number of structures. They enable the condition monitoring of structures. Monitoring systems are complex mechatronic systems with a large number of sensors for measuring different types of deformation characteristics of a structure, with all values being continuously monitored, and transferred to a central unit which performs data processing, and on the basis of the obtained results it is concluded whether the structure can withstand the predicted load. This research addresses one of the segments of the monitoring system on large-scale structures (road and rail bridges, crane girders and cranes, bucket-wheel excavators, etc.) - knowledge of vertical movements under operating load. In this type of structures, it is specific to overcome large spans (bridges, crane paths, ...) and often the space around the structures under consideration is such that it is not possible to measure global deformation values - displacements, by some conventional methods, due to inaccessible terrain (gorges, river flows, ...), or due to the occupied space under the structure (technological plants, etc.).

The research includes determination of global deformation value, vertical displacement - deflection, based on measured local deformation values, strains in the structure material. For this indirect determination of structure displacement, a numerical-mathematical algorithm was developed that, based on measured values of strains at specific points on the structure, calculates the values of structure deflection over the entire span. The values of the obtained displacements using this algorithm are compared with the values of displacements obtained by analytical expressions, as well as values obtained by direct measurement of vertical displacements in the experimental model.

\section{THE DEFORMATION BEAM THEORY}

When we talk about the deformation of the beam as a body, we start from Bernoulli's assumption that the crosssections of the beam do not deform and that during deformation they remain straight and perpendicular on the deformed axis of the beam. Bernoulli's assumption is the basic assumption of the technical theory of beam bending
[1]. Under the applied load, the beam is bent, the longitudinal axis of the beam is curved, with the fibers parallel to the axis of the beam shortening on the concave side and elongating on the convex one (Fig. 1.). This form of loading and deformation of the beam is called bending, and the beam exposed to bending is called a girder. In the cross-section of the beam, the transverse force $T$ and the bending moment $M$ act in a plane perpendicular to the plane of the cross-section of the beam. If only bending moments occur in the cross- sections of the beam, such bending of the beam is called pure bending. The effect of transverse forces on the deformation of the beam is small under the conditions of usability of the structures under exploitation loads, so it can be neglected, which is usually satisfied by Bernoulli's hypothesis.

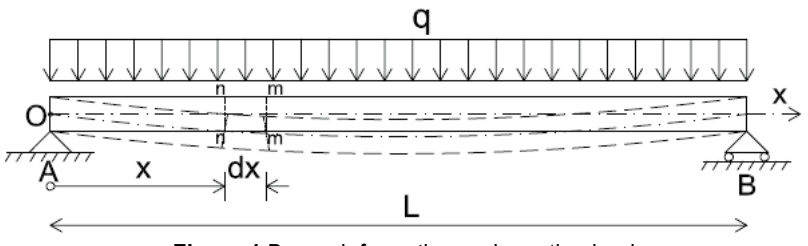

Figure 1 Beam deformation under acting load
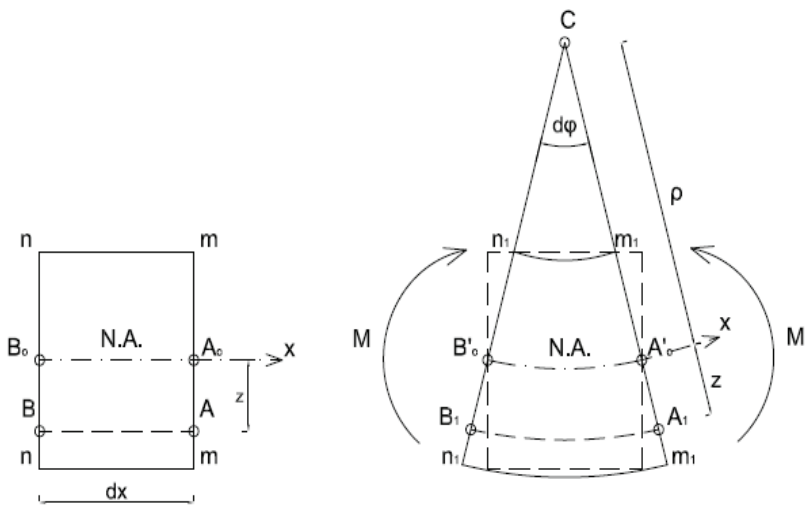

Figure 2 Beam volume element deformation

Consider a separate beam volume element between two infinitely close cross-sections $n-n$ and $m-m$. The shape of this element before and after deformation is shown in Fig. 2. Based on the known expressions of the fiber elongation relationship and the rotation angle $\mathrm{d} \varphi$, a relative extension of the fiber $A B$ is obtained at a distance $z$ from the neutral axis: 


$$
\begin{aligned}
& \varepsilon=\frac{\overline{A_{1} B_{1}}-\overline{A B}}{\overline{A B}}, \overline{A B}=\overline{A_{0} B_{0}}=\mathrm{d} x=\overline{A_{0}^{\prime} B_{0}^{\prime}}=\rho \mathrm{d} \varphi \\
& \overline{A_{1} B_{1}}=(\rho+z) \mathrm{d} \varphi \\
& \varepsilon=\frac{(\rho+z) \mathrm{d} \varphi-\rho \mathrm{d} \varphi}{\rho \mathrm{d} \varphi}=\frac{z}{\rho}
\end{aligned}
$$

For a cross-section at a distance $x$ from the beginning of the beam:

$$
\frac{1}{\rho(x)}=\frac{\varepsilon(x)}{z}
$$

Wherein: $\rho$ - radius of the beam curvature, $x$ - abscissa in the direction of the beam, $\varepsilon$ - elongation or shortening strain, $z$ - distance from neutral axis.

\section{BEAM CURVATURE FUNCTION AND VERTICAL DISPLACEMENT FUNCTION - BEAM DEFLECTION}

The procedure for obtaining the beam curvature function based on the above expressions is given in the following steps [2]. If we have a simple beam, there are two adjacent segments on that beam, $i$ and $i+1$. The beam segment $i$ extends from the left support to the middle of the beam, and the beam segment $i+1$ extends from the middle beam to the right support. The function of the curve of the segment of the beam $i$ can be described by a polynomial of the second degree:

$$
P_{i}^{2}(x)=a_{i} x^{2}+b_{i} x+c_{i}=\frac{1}{\rho_{i}(x)}
$$

Since the polynomial $P_{i}^{2}(x)$ has three unknowns, three independent measurements are required to determine these three coefficients $\left(a_{i}, b_{i}, c_{i}\right)$ for one segment of beam $i$. This means that it is necessary to know the radius values of the curve of the beam segment $i$ in three different crosssections of the beam segment $i$, located at a distance $x$ from the beginning of the beam segment $i$. The same applies to the beam segment $i+1$, except that the beam segment $i+$ 1 begins where the beam segment $i$ ends. The vertical displacement function - beam deflection is obtained by double integration of the curve function of the beam segment $i$ and the beam segment $i+1$ :

$$
P_{i}^{4}(x)=\iint P_{i}^{2}(x) \mathrm{d} x+\alpha_{i} x+\beta_{i}
$$

In order to obtain the displacement function on both segments of the beams $i$ and $i+1$, it is necessary to determine the integration constants $\alpha_{i}$ and $\beta_{i}$, by setting the following continuity conditions:

$$
P_{i}^{4}\left(X=L_{i}\right)=P_{i+1}^{4}(X=0), \text { Condition 1: An expression }
$$
of the continuity of displacement between two adjacent segments of a beam.

$$
P_{i}^{4^{\prime}}\left(X=L_{i}\right)=P_{i+1}^{4^{\prime}}(X=0) \text {, Condition } \quad 2 \text { : } \quad \text { An }
$$

expression of the slope continuity between two adjacent beam segments.

$$
P_{i}^{4}(X=0)=0, P_{i+1}^{4}\left(X=L_{i+1}\right)=0 \text {, Condition 3: Zero }
$$
displacement of boundary conditions at both ends of the beam.

The elongation or shortening strain $\varepsilon$ can be measured by a relative displacement sensor, which, when positioned in parallel with the neutral axis, measures the strain based on the measurement of changes in the length of the measuring base:

$\varepsilon=\frac{\Delta l}{l_{1}}, \Delta l=l_{2}-l_{1}$

$l_{1}$ - initial length, $l_{2}$ - length after deformation

The function of the curvature of each beam segment is a second degree polynomial in the form:

$$
P^{2}(x)=a x^{2}+b x+c
$$

Since the polynomial $P^{2}(x)$ has three unknowns, we need three independent measurements, which we get by measuring with three relative displacement sensors, and we get the following information:

$\frac{1}{\rho_{1}}:$ mean radius of curvature at $\left(x_{1}^{\prime}, x^{\prime \prime}{ }_{1}\right)$

$\frac{1}{\rho_{2}}$ : mean radius of curvature at $\left(x_{2}^{\prime}, x_{2}^{\prime \prime}\right)$

$\frac{1}{\rho_{3}}$ : mean radius of curvature at $\left(x_{3}^{\prime}, x_{3}^{\prime \prime}\right)$

Where $x_{i}^{\prime}$ and $x^{\prime \prime}{ }_{i}$ denote the left and right limits, respectively, of the sensors $i$.

The coefficients $a, b$ and $c$ represent the solutions of the following linear system of equations,

$$
\int_{x_{i}^{\prime}}^{x_{i}^{\prime \prime}}\left(a x^{2}+b x+c\right) \mathrm{d} x=\frac{1}{\rho_{i}}, \quad i=1,2,3 .
$$

the solution of which we obtain the functions of the curvature of the beam, and then by the described procedure of double integration and the determination of unknown integration constants from the established boundary conditions, we obtain the function of the deflection of the beam.

\section{CUBIC SPLINE INTERPOLATION}

The described procedure requires a complex solution (determination of coefficients $a, b$ and $c$ and determination of integration constants $\alpha_{i}$ and $\beta_{i}$ ), for two established beam segments. In this case, the function of the curvature of the beam can be assumed in the form of a second degree polynomial for a simple beam, but this is not the case for other types of static systems (beam fixed on both ends, cantilever, beam fixed on one end and supported on the second end, ..., etc.). The solution process itself is not suitable for developing an automated calculation algorithm that would collect real-time data from relative 
displacement sensors and, as a result, give values for the structure deflection function. In order to simplify the calculation, it is proposed that the values of the beam curvature function should be obtained by applying a Cubic Spline Interpolation, based on the measured strain values. This solution enables the automation of the calculation algorithm, which is a prerequisite for establishing a computer-controlled system for the continuous measurement of the displacement of structures, and by applying cubic spline interpolation, we solve the problem of the assumed shape of the curvature function of the beamtype structure for cases other than a static simple-beam system.

For a given function $\left.\left(x_{i}, f\left(x_{i}\right)\right), i=0,1, \ldots, n\right)$, it is not practical to approximate a single interpolation polynomial of degree $n$ over the entire interval $\left(x_{0}, x_{n}\right)$. A more favorable solution is to divide the interval $\left(x_{0}, x_{n}\right)$ into more subintervals. At each subinterval, the function is approximated by an interpolation polynomial. At each common point of two adjacent subintervals, both interpolation polynomials have the same value, but the first derivative at the common point is not continuous, since the values on the left and right sides of the common point are not equal. As a result of this segmental interpolation, a curve composed of parts of the polynomial, which is not smooth, is obtained. In order for the curve to be smooth, it is necessary to satisfy the continuity conditions of the first derivatives, and for the higher derivatives to be continuous [4].

For a cubic spline, through each two adjacent interpolation nodes (points) of the total number $(n+1)$ of nodes at the interval $\left(x_{0}, x_{n}\right)$, a third degree polynomial $(m$ $=3$ ) is drawn.

$P(x)=a+b x+c x^{2}+d x^{3}$

The cubic polynomial is defined by 4 coefficients. It is necessary to determine the total of $4 n$ coefficients, for a total of $n$ cubic interpolation polynomials at the interval $\left(x_{0}\right.$, $\left.x_{n}\right)$. If we are given $(n+1)$ points and values:

$\left[\left(x_{0}, f\left(x_{0}\right),\left(x_{1}, f\left(x_{1}\right), \ldots,\left(x_{n}, f\left(x_{n}\right)\right]\right.\right.\right.$

we will form $n$ cubic polynomials. For $j=0,1, \ldots, n-1$ we assume:

$$
\begin{aligned}
& S_{j}=a_{j}+b_{j}\left(x-x_{j}\right)+c_{j}\left(x-x_{j}\right)^{2}+d_{j}\left(x-x_{j}\right)^{3} \\
& h_{j}=x_{j+1}-x_{j} \\
& \text { za } a=x_{0}<x_{1}<, \ldots, \quad<x_{n}=b \\
& S(x)=\left\{\begin{array}{l}
a_{0}+b_{0}\left(x-x_{0}\right)+c_{0}\left(x-x_{0}\right)^{2}+d_{0}\left(x-x_{0}\right)^{3}, x_{0} \leq x \leq x_{1} \\
a_{i}+b_{i}\left(x-x_{i}\right)+c_{i}\left(x-x_{i}\right)^{2}+d_{i}\left(x-x_{i}\right)^{3}, x_{i} \leq x \leq x_{i+1} \\
a_{n-1}+b_{n-1}\left(x-x_{n-1}\right)+c_{n-1}\left(x-x_{n-1}\right)^{2}+d_{n-1}\left(x-x_{n-1}\right)^{3}, x_{n-1} \leq x \leq x_{n}
\end{array}\right.
\end{aligned}
$$

We need to find unknown $a_{j}, b_{j}, c_{j}$ and $d_{j}$ ( $4 n$ total unknown). Solving these equations is more transparent if presented in matrix form. The system of $n+1$ equation in matrix form is:
$[\boldsymbol{A}] \cdot[\boldsymbol{C}]=[\boldsymbol{Y}]$, where is

$\boldsymbol{A}=\left[\begin{array}{cccccccc}1 & 0 & 0 & 0 & . & . & . & 0 \\ h_{0} & 2\left(h_{0}+h_{1}\right) & h_{1} & 0 & . & . & . & 0 \\ 0 & h_{1} & 2\left(h_{1}+h_{2}\right) & h_{2} & 0 & . & . & 0 \\ \cdot & . & . & . & . & . & . & . \\ \cdot & . & . & . & . & . & . & . \\ . & . & . & . & . & . & . & . \\ 0 & 0 & 0 & . & . & h_{n-2} & 2\left(h_{n-2}+h_{n-1}\right) & h_{n-1} \\ 0 & 0 & 0 & . & . & . & . & 1\end{array}\right]$

$$
\boldsymbol{C}=\left[\begin{array}{l}
c_{0} \\
c_{1} \\
\cdot \\
c_{n-1} \\
c_{n}
\end{array}\right], \boldsymbol{Y}=\left[\begin{array}{c}
0 \\
\frac{3}{h_{1}}\left(a_{2}-a_{1}\right)-\frac{3}{h_{0}}\left(a_{1}-a_{0}\right) \\
\cdot \\
\frac{3}{h_{n-1}}\left(a_{n}-a_{n-1}\right)-\frac{3}{h_{n-2}}\left(a_{n-1}-a_{n-2}\right) \\
0
\end{array}\right]
$$

Since $a_{j}$ for $j=0,1, \ldots, n$, are known quantities, when we solve the system of equations by $c_{j}$ for $j=0,1, \ldots, n$, then the coefficients are:

$$
\begin{aligned}
& b_{j}=\frac{1}{h_{j}}\left(a_{j+1}-a_{j}\right)-\frac{h_{j}}{3}\left(c_{j+1}+2 c_{j}\right) \\
& d_{j}=\frac{1}{3 h_{j}}\left(c_{j+1}-c_{j}\right) \text { for } j=0,1, \ldots, n-1
\end{aligned}
$$

\section{NUMERICAL DEFLECTION ALGORITHM OBTAINED BY APPLYING CUBIC SPLINE INTERPOLATION}

The calculation algorithm will be shown on the beamtype structure model, in static system of a simple beam with a span length $L=5000 \mathrm{~mm}$, made of steel IPB (HEB) 200 profile.

A constant distributed load of $q=10 \mathrm{kN} / \mathrm{m}$ acts on the beam, resulting in maximum stresses at the mid-span cross section of $\sigma_{\max / \min }= \pm 54,0 \mathrm{MPa}$. The actual stresses under distributed load are below the limit of proportionality, which in our case is $\sigma_{\mathrm{p}}= \pm 160,0 \mathrm{MPa}$, for the type of material the beam is made of (Steel S235). At these stress levels, the limit of proportionality is not exceeded, ie. the stress-strain curve is linear and the material is in the linearelastic region, thus fulfilling the conditions for adopted Bernoulli's hypothesis. Also, the analytic expressions for the displacement due to the action of the load are derived assuming a linear-elastic state, so it is justified to compare the displacement values obtained by the analytical expressions and the proposed calculation algorithm.

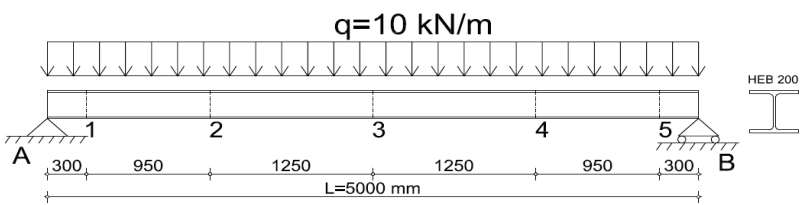

Figure 3 Simple beam model

The cross-sections, in which the strain is measured in the upper and lower fibers, are at the following distances 
from the left support (Fig. 3): $x_{1}=300 \mathrm{~mm}, x_{2}=1250 \mathrm{~mm}$, $x_{3}=2500 \mathrm{~mm}, x_{4}=3750 \mathrm{~mm}$ and $x_{5}=4700 \mathrm{~mm}$.

In order to verify the accuracy of the algorithm, analitacal values of strain in the upper and lower fiber of the cross-sections under acting load, are taken as measured values of strain. The steps of calculation of Cubic spline interpolation coefficients are presented in Tab. 1 - Tab. 3.

Table 1 Strain values in upper and lower fibers

\begin{tabular}{|c|c|c|c|c|}
\hline $\begin{array}{l}\text { Cross- } \\
\text { section }\end{array}$ & $\begin{array}{l}\text { Position } \\
\text { from left }\end{array}$ & $\begin{array}{l}\text { Distance } \\
\text { between }\end{array}$ & $\begin{array}{l}\text { Strain in upper } \\
\text { fiber }\end{array}$ & $\begin{array}{c}\text { Strain in lower } \\
\text { fiber }\end{array}$ \\
\hline $\mathrm{Nr}$. & $\begin{array}{l}\text { support } \\
X_{i} / \mathrm{mm}\end{array}$ & $\begin{array}{l}\text { fibers } \\
D / \mathrm{mm}\end{array}$ & $\varepsilon_{i g} / \mathrm{mm} / \mathrm{mm}$ & $\varepsilon_{i d} / \mathrm{mm} / \mathrm{mm}$ \\
\hline 0 & 0 & \multirow{7}{*}{200} & 0 & 0 \\
\hline 1 & 300 & & $-5,9 \mathrm{e}-05$ & $5,9 \mathrm{e}-05$ \\
\hline 2 & 1250 & & $-2,0 \mathrm{e}-04$ & $2,0 \mathrm{e}-04$ \\
\hline 3 & 2500 & & $-2,6 \mathrm{e}-04$ & $2,6 \mathrm{e}-04$ \\
\hline 4 & 3750 & & $-2,0 \mathrm{e}-04$ & $2,0 \mathrm{e}-04$ \\
\hline 5 & 4700 & & $-5,9 \mathrm{e}-05$ & $5,9 \mathrm{e}-05$ \\
\hline 6 & 5000 & & 0 & 0 \\
\hline
\end{tabular}

Table 2 Values of curve radius and beam curvature

\begin{tabular}{|c|c|c|c|}
\hline $\begin{array}{c}\text { Cross- } \\
\text { section }\end{array}$ & $\begin{array}{c}\text { Distance of neutral } \\
\text { axis from bottom } \\
\text { edge }\end{array}$ & $\begin{array}{c}\text { Beam curve } \\
\text { radius }\end{array}$ & $\begin{array}{c}\text { Beam } \\
\text { curvature }\end{array}$ \\
\hline Nr. & $z / \mathrm{mm}$ & $\rho_{i}$ & $1 / \rho_{i}$ \\
\hline 0 & 100 & 0,0 & 0.0 \\
\hline 1 & 100 & $1,7 \mathrm{e}+06$ & $5,9 \mathrm{e}-07$ \\
\hline 2 & 100 & $5,1 \mathrm{e}+05$ & $2,0 \mathrm{e}-06$ \\
\hline 3 & 100 & $3,8 \mathrm{e}+05$ & $2,6 \mathrm{e}-06$ \\
\hline 4 & 100 & $5,1 \mathrm{e}+05$ & $2,0 \mathrm{e}-06$ \\
\hline 5 & 100 & $1,7 \mathrm{e}+06$ & $5,9 \mathrm{e}-07$ \\
\hline 6 & 100 & 0,0 & 0.0 \\
\hline
\end{tabular}

The subintervals of the interpolation polynomial corresponding to the distances between the adopted beam cross sections are shown in Tab. 3 .

Table 3 Interpolation steps and Cubic spline interpolation coefficients

\begin{tabular}{|c|c|c|c|c|c|}
\hline Cross- section & $\begin{array}{c}\text { Interp. } \\
\text { step }\end{array}$ & $\begin{array}{c}\text { Known } \\
\text { coefficient }\end{array}$ & \multicolumn{3}{|c|}{$\begin{array}{c}\text { Cubic spline interpolation } \\
\text { coefficients }\end{array}$} \\
\hline $\mathrm{Nr}$. & $h_{j}$ & $a_{j}$ & $b_{j}$ & $c_{j}$ & $d_{j}$ \\
\hline 0 & 300 & 0 & $2,0 \mathrm{e}-09$ & $-2,8 \mathrm{e}-26$ & $-5,3 \mathrm{e}-16$ \\
\hline 1 & 950 & $5.9 \mathrm{e}-07$ & $1,9 \mathrm{e}-09$ & $-4,7 \mathrm{e}-13$ & $2,4 \mathrm{e}-17$ \\
\hline 2 & 1250 & $2,0 \mathrm{e}-06$ & $1,0 \mathrm{e}-09$ & $-4,0 \mathrm{e}-13$ & $-5,6 \mathrm{e}-18$ \\
\hline 3 & 1250 & $2,6 \mathrm{e}-06$ & $0,0 \mathrm{e}+00$ & $-4,2 \mathrm{e}-13$ & $5,6 \mathrm{e}-18$ \\
\hline 4 & 950 & $2,0 \mathrm{e}-06$ & $-1,0 \mathrm{e}-09$ & $-4,0 \mathrm{e}-13$ & $-2,4 \mathrm{e}-17$ \\
\hline 5 & 300 & $5,9 \mathrm{e}-07$ & $-1,9 \mathrm{e}-09$ & $-4,7 \mathrm{e}-13$ & $5,3 \mathrm{e}-16$ \\
\hline 6 & & 0 & - & 0,0 & - \\
\hline
\end{tabular}

With the known values of the coefficients $a_{i}, b_{i}, c_{i}$ and $d_{i}$, the values of cubic polynomials are formed at subintervals:

$$
S(x)=\left\{\begin{array}{l}
0 \leq x \leq 300 \\
300 \leq x \leq 1250 \\
1250 \leq x \leq 2500 \\
2500 \leq x \leq 3750 \\
3750 \leq x \leq 4700 \\
4700 \leq x \leq 5000
\end{array}\right.
$$

In this way, the values of the beam curvature function over the total span are obtained. Further procedure is reduced to numerical double integration of the beam curvature function, which as a result provides the values of the beam deflection function due to the acting load. The integration method uses the trapezoidal rule:
$I_{n}=\int_{x_{n-1}}^{x_{n}} y \mathrm{~d} x=\frac{h}{2}\left(y_{n-1}+y_{n}\right)$

Comparative values of the beam deflection obtained by analytical expressions and values obtained by applying the described algorithm are shown in Tab. 4.

Table 4 Analytical and calculated deflection values

\begin{tabular}{|c|c|c|c|c|}
\hline $\begin{array}{c}\text { Cross- } \\
\text { section }\end{array}$ & $\begin{array}{c}\text { Position } \\
\text { from left } \\
\text { support } X_{i} / \\
\mathrm{mm}\end{array}$ & $\begin{array}{c}\text { Deflection } \\
\text { values } \\
\text { Analytical / } \\
\mathrm{mm}\end{array}$ & $\begin{array}{c}\text { Deflection } \\
\text { values } \\
\text { proposed } \\
\text { algorithm / } \\
\mathrm{mm}\end{array}$ & $\begin{array}{c}\text { Deviation / } \\
\mathrm{mm}\end{array}$ \\
\hline 0 & 0 & 0 & 0 & 0 \\
\hline 1 & 300 & 1,296 & 1,296 & 0 \\
\hline 2 & 1250 & 4,844 & 4,844 & 0 \\
\hline 3 & 2500 & 6,799 & 6,798 & 0,001 \\
\hline 4 & 3750 & 4,844 & 4,844 & 0 \\
\hline 5 & 4700 & 1,296 & 1,296 & 0 \\
\hline 6 & 5000 & 0 & 0 & 0 \\
\hline
\end{tabular}

From the presented results, it can be seen that there are practically no deviations in the values of the beam deflection. The only deviation occurs in the cross - section in the mid-span of the beam, but the magnitude of this deviation is very small $(0,001 \mathrm{~mm})$, and this magnitude has no effect on the quality of the results obtained, since the deflection values of the structures are measured in millimeters or ten parts of a millimeter.

\section{EXPERIMENTAL TESTING OF THE BEAM-TYPE STRUCTURE MODEL}

Verification of proposed algorithm was performed on experimental model, which fully corresponds to analytical model, beam-type structure position in a static system of simple beam, with span of $L=5000 \mathrm{~mm}$, made of steel profile IPB (HEB) 200.
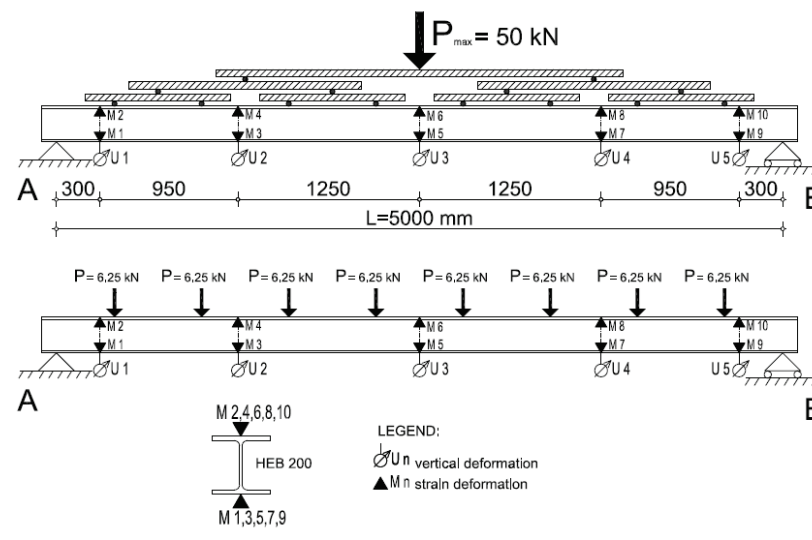

Figure 4 Schematic diagram of experimental model setup

Measuring sections are installed on the beam at the same distances from left support, in which the strains are measured by means of electrically resistant measuring gages - strain gauges [5], at the same cross-sectional positions. In addition to strain measurements, displacement measurements were also performed using inductive displacement transducers at the same cross-section positions, so that the results of the calculation can be compared using the proposed algorithm and directly 
measured values. The arrangement of the experimental model is shown in Fig. 4. and Fig. 5.

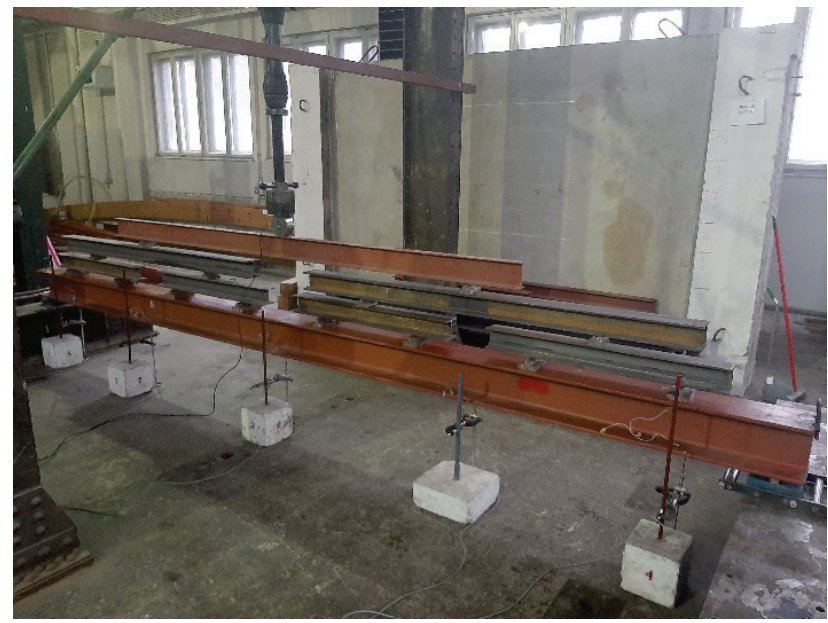

Figure 5 Experimental model setup

The model was loaded with a hydraulic press $50 \mathrm{kN}$ point load, and the load transfer on the beam was performed by auxiliary elements whose role was to simulate a uniformly distributed load, in the close by amount of $q=10 \mathrm{kN} / \mathrm{m}$. The weight of the auxiliary elements is negligible in relation to the value of the point load. In this case, maximum stresses at the mid-span cross section were $\sigma_{\max / \min }= \pm 57,0 \mathrm{MPa}$, and they are also below the limit of proportionality, $\sigma_{\mathrm{p}}= \pm 160,0 \mathrm{MPa}$, for the type of material the beam is made of (Steel S235). Limit of proportionality is not exceeded, and the stress-strain curve is linear and the material is in the linear-elastic region.

For direct displacement measurement, inductive displacement transducers WA $100 \mathrm{HBM}$ (Fig. 6) were used, and electrical resistance extensometers - strain gauges PL 10 TML were used to measure the strains in the upper and lower beam fibers. The strain gauges were mounted on the upper and lower legs of the steel profile IPB (HEB) 200.

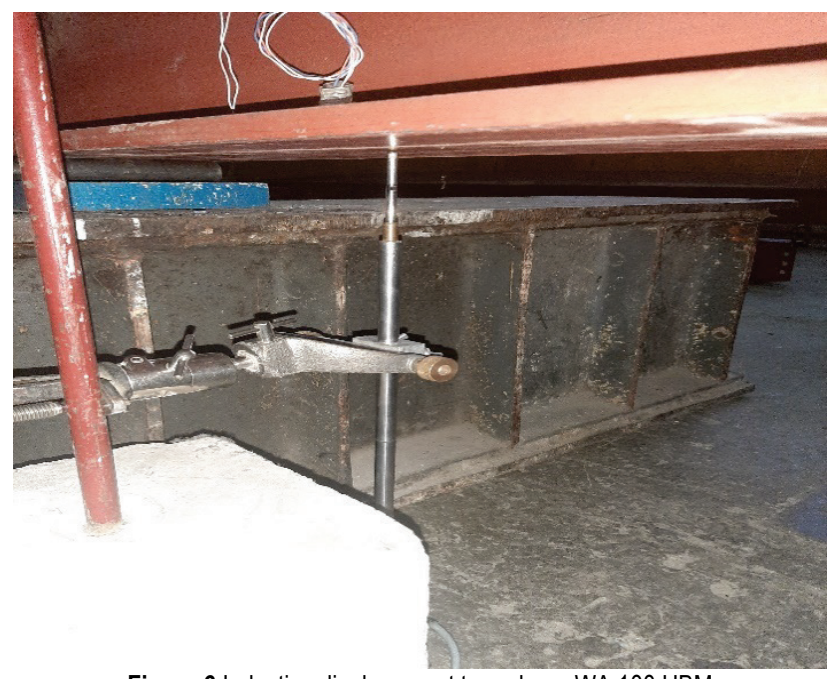

Figure 6 Inductive displacement transducer WA 100 HBM

Point load, applied with hydraulic press was measured by load cell TS 10 AEP, with capacity of $100 \mathrm{kN}$ (Fig. 7). The measurements were conducted by the Quantum MX840B HBM measurement unit [6], which together with the notebook and the Catman AP HBM measurement software, make the data acquisition system.

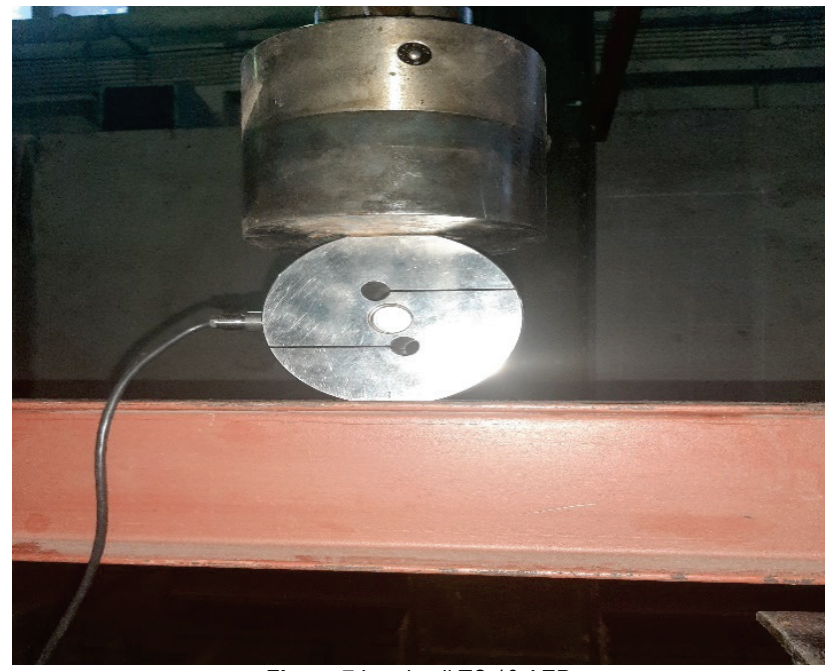

Figure 7 Load cell TS 10 AEP

After all the sensors and auxiliary elements were installed, a gradual force was applied. The maximum value of the point load came in four steps. After reaching the maximum load value and stabilisation of the deformation characteristics of the beam-type structure, the measurement of strains and deflections was started.

Comparative values of beam deflection obtained by the proposed algorithm and values obtained by direct measurement are shown in Tab. 5, and in the diagram - Fig. 8:

Table 5 Deflection values - by algorithm and measured

\begin{tabular}{|c|c|c|c|c|c|}
\hline $\begin{array}{c}\text { Cross- } \\
\text { section }\end{array}$ & $\begin{array}{c}\text { Position } \\
\text { from left } \\
\text { support } \\
X_{i} / \mathrm{mm}\end{array}$ & $\begin{array}{c}\text { Deflection } \\
\text { values } \\
\text { Directly } \\
\text { measured } / \\
\mathrm{mm}\end{array}$ & $\begin{array}{c}\text { Deflection } \\
\text { values } \\
\text { proposed } \\
\text { algorithm } / \\
\mathrm{mm}\end{array}$ & $\begin{array}{c}\text { Deviation } \\
/ \mathrm{mm}\end{array}$ & $\begin{array}{c}\text { Deviation } \\
/ \%\end{array}$ \\
\hline 0 & 0 & 0 & 0 & 0 & 0 \\
\hline 1 & 300 & 1,22 & 1,19 & 0,03 & 2,5 \\
\hline 2 & 1250 & 4,30 & 4,39 & 0,09 & 2,1 \\
\hline 3 & 2500 & 6,14 & 6,11 & 0,03 & 0,5 \\
\hline 4 & 3750 & 4,34 & 4,37 & 0,03 & 0,7 \\
\hline 5 & 4700 & 1,24 & 1,19 & 0,05 & 4,0 \\
\hline 6 & 5000 & 0 & 0 & 0 & 0 \\
\hline
\end{tabular}

DIAGRAM OF GIRDER VERTICAL DEFLECTION UNDER TEST LOAD $-P=50 \mathrm{kN}$

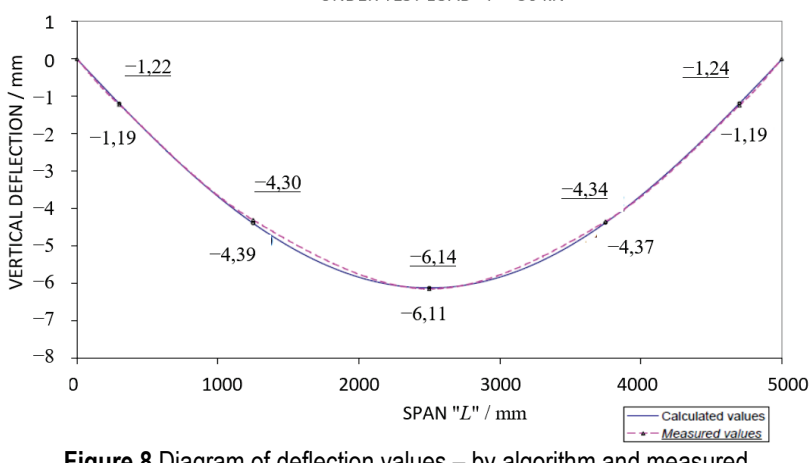

Figure 8 Diagram of deflection values - by algorithm and measured

\section{CONCLUSION}

The main task of this research was to create a calculation algorithm that indirectly calculates the values of vertical deflection of a beam-type structure, based on 
known strain values under acting load. In this paper, a calculation algorithm is proposed, which, starting from the known values of the strains of the loaded beam-type structure, using a cubic spline interpolation to interpolate the curve function of the beam and double integration of the formed function, gives as a result the value of the vertical displacement - the beam-type structure deflection.

On the basis of the set goals and mentioned way of the paper the following conclusions can be drawn:

1. If we know the values of the strains in the upper and lower fibers of the cross-section of the beam-type structure, due to the acting load, we also know the value of the radius of curvature of the beam in that cross-section,

2. By knowing the radius of curvature of the beamtype structure in several cross sections distributed along the length of the beam, it is possible to approximate the function of the curvature of the beam by applying a cubic spline interpolation,

3. By applying the double integration procedure of the beam curvature function, the vertical deflection function of the beam is obtained,

4. Proposed calculation algorithm approximates the beam curvature function. By applying the double integration procedure the function of the loaded beam vertical deflection is calculated.

5. In experimental testing on the adopted model, the deflection values obtained by the proposed calculation algorithm largely coincide with the deflection values of the beam obtained by direct measurement (relative error is less than $0,5 \%$ ).

6. The deviations are slightly larger in the areas adjacent to the beam supports. This could be corrected by increasing the number of measurement cross-sections for strain measurements in support zones. In that way we will obtain a more accurate beam curvature function, which better describes the deformation state of the beam in the support zones.

7. The applied load on the experimental model is such that the stress state in the base material of the beam is in linear-elastic region, ie. the stress-strain curve is linear.

8. The proposed calculation algorithm of vertical displacement, for the base material in the linear-elastic region, provides results with satisfactory accuracy.

Further research will focus on the application of the proposed algorithm to other basic beam static systems (beam fixed at both ends, beam fixed at one end and supported at the second end, cantilever beam, continuous beam, etc.). The plan is to extend the use of proposed algorithm to all types of static systems, including bucket wheel excavators lattice structures [7].

In further study, the proposed calculation algorithm will be checked for cases where in some cross sections of the beam-type structure, due to the acting load, the reached stress level is very close to the limit of proportionality, and then when this limit is exceeded.

The stresses in real structures under the action of the workload are usually below the limit of proportionality, but in certain situations in some segments of the structure, the limit of proportionality can be exceeded, thus creating conditions for plastic deformation of the structure base material, which can ultimately lead to structural failure. The proposed calculation algorithm, together with the strain sensors installed on the considered structure, can indicate the appearance of stress levels that are above the limit of proportionality and thus prevent possible structural damage.

\section{Acknowledgements}

This work has been performed within the projects TR35040 and 174004 which are supported by the Ministry of Education and Science of the Republic of Serbia, whose financial involvement is gratefully acknowledged.

\section{REFERENCES}

[1] Đurić, M. (1979). Statika konstrukcija. Građevinska knjiga Beograd, 6-8.

[2] Vurpilot, S., Krueger, G., Benouaich, D., Clement, D., \& Inaudi, D. (1998). Vertical Deflection of a Pre-Stressed Concrete Bridge Obtained Using Deformation Sensors and Inclinometer Measurements. ACI Structural Journal, 95(5), 518-526. https://doi.org/10.14359/566

[3] Kim, N. S. \& Cho, N. S. (2004). Estimated Deflection of a Simple Beam Model Using Fiber Optic Bragg-grating Sensors. Experimental Mechanics, 44(4), 433-439. https://doi.org/10.1177/0014485104045431

[4] Pollock, D. S. G. (1999). Smoothing With Cubic Splines. Queen Mary and Westfield College, The University of London, 2-5. https://doi.org/10.1016/B978-012560990-6/50013-0

[5] Hoffmann, K. (1989). An Introduction to Measurements using Strain Gauges. Hottinger Baldwin Messtechnik $\mathrm{GmbH}$.

[6] Operating Manual Quantum X (2016). Hottinger Baldwin Messtechnik GmbH. Retrived from: https://www.hbm.com/ en/4246/support-downloads-quantumx-somatxr/

[7] Petrović, B., Petrović, A., Ignjatović, D., Grozdanović, I., Kozak, D., \& Katinić, M. (2016). Assessment of the maximum possible extension of bucket wheel SchRs740 boom based on static and dynamic calculation. Technical Gazzete, 23(4), 1233-1238. https://doi.org/10.17559/TV-20151123152659

\section{Contact information:}

M.Sc. Željko FLAJS, Ph.D. Student

(Corresponding author)

Institute IMS

Bul. vojvode Mišića 43, 11000 Belgrade, Serbia

E-mail: zeljko.flajs@institutims.rs

Dr. Emil VEG, Assistant Professor

University of Belgrade,

Faculty of Mechanical Engineering,

Kraljice Marije 16, 11000 Belgrade, Serbia

E-mail: eveg@mas.bg.ac.rs

Dr. Nenad GUBELJAK, Full Professor

University of Maribor,

Faculty of Mechanical Engineering,

Smetanova ul. 17, 20000 Maribor, Slovenia

E-mail: nenad.gubeljak@um.si

Dr. Goran ŠINIKOVIĆ, Associate Professor

University of Belgrade,

Faculty of Mechanical Engineering,

Kraljice Marije 16, 11000 Belgrade, Serbia

E-mail: gsinikovic@mas.bg.ac.rs 